\title{
Percentage of Hormone Receptor Positivity in Breast Cancer Provides Prognostic Value: A Single-Institute Study
}

\author{
Richard Sleightholm ${ }^{\mathrm{a}, \mathrm{c}}$, Beth K. Neilsen ${ }^{\mathrm{a}, \mathrm{c}}$, Safwan Elkhatib ${ }^{\mathrm{a}}$, Laura Flores ${ }^{\mathrm{a}}$, Saihari Dukkipatia, \\ Runze Zhao ${ }^{\mathrm{a}}$, Songita Choudhury ${ }^{\mathrm{a}}$, Bret Gardner ${ }^{\mathrm{a}}$, Joey Carmichael ${ }^{\mathrm{a}}$, Lynette Smith ${ }^{\mathrm{b}}$, \\ Nathan Bennion ${ }^{\text {a }}$, Andrew Wahl ${ }^{\text {a }}$, Michael Baine ${ }^{\text {a, d }}$
}

\begin{abstract}
Background: A majority of breast cancer tumors express estrogen receptor (ER) and/or progesterone receptor (PR); however, the percentage of cancer cells expressing these receptors can range from $0-100 \%$. The prognostic and therapeutic impact of the percentage of cells expressing hormone receptors in breast cancer is not fully understood.
\end{abstract}

Methods: A retrospective analysis of 411 breast cancer patients who were treated at the University of Nebraska Medical Center between 2010 and 2017 was performed. Patient tumors were evaluated for percentage of cells expressing ER and PR in conjunction with clinical outcomes.

Results: Patient tumors demonstrated a highly bimodal pattern of ER and PR staining with a majority of tumors demonstrating either a high percentage $(>80 \%$ of cells) or lack of cells $(0 \%)$ staining for ER or PR. An increase in the percentage of ER positivity correlated with decreased local recurrence and improved overall survival. An increase in the percentage of PR positivity demonstrated a trend towards decreased local recurrence and improved overall survival, but was not statistically significant.

Conclusions: Results based on both continuous and categorical evaluation of ER expression revealed that increasing expression correlated with improved patient outcomes. Similar evaluation of PR expression demonstrated a trend towards improved patient outcomes though not statistically significant. These findings suggest that the degree of

Manuscript submitted December 2, 2020, accepted December 22, 2020

Published online January 12, 2021

aDepartment of Radiation Oncology, University of Nebraska Medical Center, Omaha, NE, USA

bDepartment of Statistics, University of Nebraska Medical Center, Omaha, NE, USA

${ }^{\mathrm{c}}$ These authors contributed equally.

${ }^{\mathrm{d} C o r r e s p o n d i n g ~ A u t h o r: ~ M i c h a e l ~ B a i n e, ~ D e p a r t m e n t ~ o f ~ R a d i a t i o n ~ O n c o l o g y, ~}$ 986861 Nebraska Medical Center, University of Nebraska Medical Center, Omaha, NE 68198-686, USA. Email: mbaine@unmc.edu

doi: https://doi.org/10.14740/jocmr4398 hormone receptor positivity and not a Boolean representation of positivity could provide additional prognostic value in the treatment and management of breast cancer.

Keywords: Estrogen progesterone receptor percent positivity; Breast cancer; Radiation therapy; Locoregional recurrence; Distant recurrence; Survival

\section{Introduction}

Breast cancer is the most common cancer in women worldwide $[1,2]$. In the majority of breast cancer patients, estrogen receptor (ER) and/or progesterone receptor (PR) are overexpressed and promote the development of breast cancer [3, 4]. Thus, multiple endocrine-targeted therapies such as selective ER modulator (e.g., tamoxifen), aromatase inhibitors (e.g., anastrozole, letrozole), and selective ER degraders (e.g., fulvestrant) have been developed to interfere with ER signaling, block estrogen synthesis, or promote estrogen degradation, respectively [5]. Given that these therapies are effective in hormone receptorpositive breast cancers, the ER and PR status of breast cancers is vital information for predicting patient prognosis and guiding patient management in invasive breast cancer.

Immunohistochemistry (IHC) is now used by most clinical laboratories as the "gold standard" to evaluate the expression of ER and PR in patient samples [6, 7]. In this assay, a cut-off point is needed to define the level at which a tumor is considered positive for hormone receptor expression. The American Society of Clinical Oncology and the College of American Pathologists recommend samples be considered hormone receptor positive if as little as $1 \%$ of tumor nuclei stain positively by IHC [8]. This is supported by evidence that patients with low level of receptor positivity (1-10\%) still may benefit considerably from endocrine-based therapies, and have a significantly better response than those with ER-negative tumors [9, 10]. However, several other studies support a higher cut-off point, and in clinical practice a range of thresholds are used to establish hormone receptor positivity, which may be dependent on the pathologic method utilized to measure hormone receptor positivity $[11,12]$. Additionally, multiple groups have ques- 
tioned the therapeutic benefits of hormonal therapy in patients with a low percentage of cells staining positive for ER [10]. Evidence suggests that in the adjuvant setting, up to $50 \%$ of patients with ER-positive breast cancer may relapse despite hormonal inhibition therapy suggesting the quantification of the positivity or other factors are likely to also be contributing. As such, using $1 \%$ as a cutoff for ER positivity has been challenged and an alternate cutoff for positivity set at $10 \%$ positivity has been commonly suggested [13]. In several comprehensive studies, tumors with a low level of ER-staining (1-10\%) share more clinical and pathologic characteristics with ERnegative than to ER-positive tumors, which show little benefit from endocrine therapy [13-16]. Therefore, further evaluation on the characteristics, patient prognoses, and treatment efficacy in low-ER-staining tumors is warranted.

Some investigation into ER expression has been previously performed. Hill et al found the intensity, rather than percent cellular expression was correlated to survival, though progesterone expression was not taken into consideration [17]. Others have shown that PR expression in the absence of estrogen remains correlated to clinical outcomes [18]. Further studies have shown co-expression of androgen receptors with ER, suggesting crosstalk may play an important role in treatment response and outcomes [19]. Nevertheless, studies on the association between the degree of both ER and PR positivity and the level of response to endocrine therapies are still lacking. Therefore, we sought to evaluate the relationships between the hormone receptor relative positivity (percentage of positive cells) and patient outcomes in the context of standard of care therapy.

\section{Materials and Methods}

A retrospective analysis was performed on breast cancer patients who were consulted for radiation therapy (RT) at the University of Nebraska Medical Center (UNMC) between 2010 and 2017. This study was approved by and conducted in compliance with all ethical standards of UNMC on human subjects including UNMC's Institutional Review Board as well as the Helsinki Declaration. Patients had to have pathologically confirmed disease and received RT as part of their initial treatment plan at time of diagnosis. Those who elected not to undergo RT, did not finish their planned course, or received intraoperative radiation or brachytherapy were also excluded from the present study.

A comprehensive evaluation was performed evaluating the demographics (age, sex, year of diagnosis and treatment, histology, stage, etc.), tumor pathology, treatment (surgical intervention, chemotherapy, etc.), details of their radiation treatment (dose, fractionation pattern, tumor cavity boost, etc.), and progression and survival outcomes of our cohort. Percentage of ER and PR staining was established by a board-certified pathologist for all samples.

All data were analyzed using SAS (version 9.4, SAS/STAT 14.3). Patient and cancer characteristics were reported in Table 1. Continuous variables, e.g., age, were compared between the two groups using a two-tailed student's $t$-test. Chi-squared testing was used to compare all dichotomous variables between groups. Progression-free survival was defined as months from the date of diagnosis until radiological or pathological evidence of recurrence, last follow-up visit, or date of death. Time to local-regional recurrence and distant recurrence was assessed both as disease-specific recurrence, treating death without the identification of disease recurrence as censored. Similarly, survival was defined as months from the date of diagnosis until date of death or last date of follow-up. Patients who were alive at the end of the study or lost to follow-up were treated as censored. Progression free survival and survival were estimated using the Kaplan-Meier (KM) method, and the logrank test was used to evaluate statistically significant differences in progression free survival or overall survival between cohorts. Further use of Cox proportional hazard $(\mathrm{PH})$ regression was applied to control for variables known to influence survival, i.e., age, stage, etc., and assess any difference between treatment cohorts.

All statistical tests were conducted in a two-sided manner, and statistical results with $\mathrm{P}<0.05$ were considered statistically significant. Review of all medical records and the subsequent analyses were approved by the appropriate institutional review committee and met the guidelines of their responsible governmental agency.

\section{Results}

Overall, 411 patients were included in the cohort. Median patient age was 58 and median overall follow-up time was 36.6 months. Median year of diagnosis was 2014. Additional general demographic and tumor characteristics can be found in Table 1.

\section{Effects of stage on local, distant, and overall survival in breast cancer}

No significant association was found between stage and local recurrence ( $\mathrm{P}=0.1957)$ (Fig. 1a); however, increased stage was significantly correlated with both distant recurrence $(\mathrm{P}<$ $0.001)$ and overall survival $(\mathrm{P}=0.003)$ (Fig. 1b, c).

\section{Distribution of ER and PR percent positivity in breast can- cer}

The distribution of both ER and PR percent positivity had a bimodal distribution with a substantial portion of patients being either negative or having a high level $(\geq 80 \%)$ of ER and/ or PR staining. Based on these bimodal distributions, in order to establish similar sized groups, three subgroups were established based on the level of ER or PR positivity: $0 \%, 1-79 \%$, and $\geq 80 \%$. In regards to ER positivity, more than $20 \%$ of the cohort was negative while approximately $66 \%$ of the cohort had $\geq 80 \%$ ER positivity (mean: $93 \%$, median: $95 \%$ ) and $10 \%$ of the cohort had values between 1-79\% (mean: 49\%, median: $60 \%$ ) (Supplementary Material 1, www.jocmr.org). In regards to PR positivity, approximately $33 \%$ of the cohort was negative while just $38 \%$ of the cohort had $\geq 80 \%$ positivity (mean: 91\%, median: 90\%) (Supplementary Material 1, www.jocmr. 
Table 1. Demographics and Tumor Characteristics of Breast Cancer Patients

\begin{tabular}{|c|c|}
\hline & Entire cohort $(n=411)$ \\
\hline Age, median (range) & $58.0(19.8-88.1)$ \\
\hline \multicolumn{2}{|l|}{ Sex } \\
\hline BMI, median (interquartile range) & $28.7(25.2-34.1)$ \\
\hline Smoking status, \# at diagnosis (\%) & $49(15.0 \%)$ \\
\hline Follow-up (months), median (mean)/(range) & $36.6(44.1) /(4.7-304.9)$ \\
\hline \multicolumn{2}{|l|}{ Histology } \\
\hline Invasive ductal carcinoma & 350 \\
\hline Invasive lobular carcinoma & 48 \\
\hline Inflammatory & 2 \\
\hline \multicolumn{2}{|l|}{ Grade } \\
\hline I & 83 \\
\hline II & 154 \\
\hline III & 168 \\
\hline Unknown & 6 \\
\hline \multicolumn{2}{|l|}{ T stage } \\
\hline $\mathrm{T} 0$ & 2 \\
\hline T1a & 32 \\
\hline $\mathrm{T} 4 \mathrm{c}$ & 1 \\
\hline $\mathrm{T} 4 \mathrm{~d}$ & 5 \\
\hline Unknown & 2 \\
\hline \multicolumn{2}{|l|}{ Overall stage } \\
\hline I & 184 \\
\hline II & 159 \\
\hline III & 68 \\
\hline
\end{tabular}

org). The remaining 29\% fell into the $1-79 \%$ cohort (mean: $42 \%$, median: $50 \%$ ).

\section{Outcomes relative to ER percent positivity in breast cancer}

Prior to evaluating the effects on outcomes based on the level of ER positivity, patient and tumor characteristics were com- pared between these subgroups (Supplementary Material 2, www.jocmr.org). This analysis revealed that age, year of diagnosis, length of follow-up, histological subtype, grade and T stage, but not overall stage, were significantly different between subgroups. Additionally, the use of hormone inhibition therapy (selective ER modulators or aromatase inhibitors) was significantly different between subgroups. It was nearly ubiquitously used in ER-positive patients, such that more than $90 \%$ 


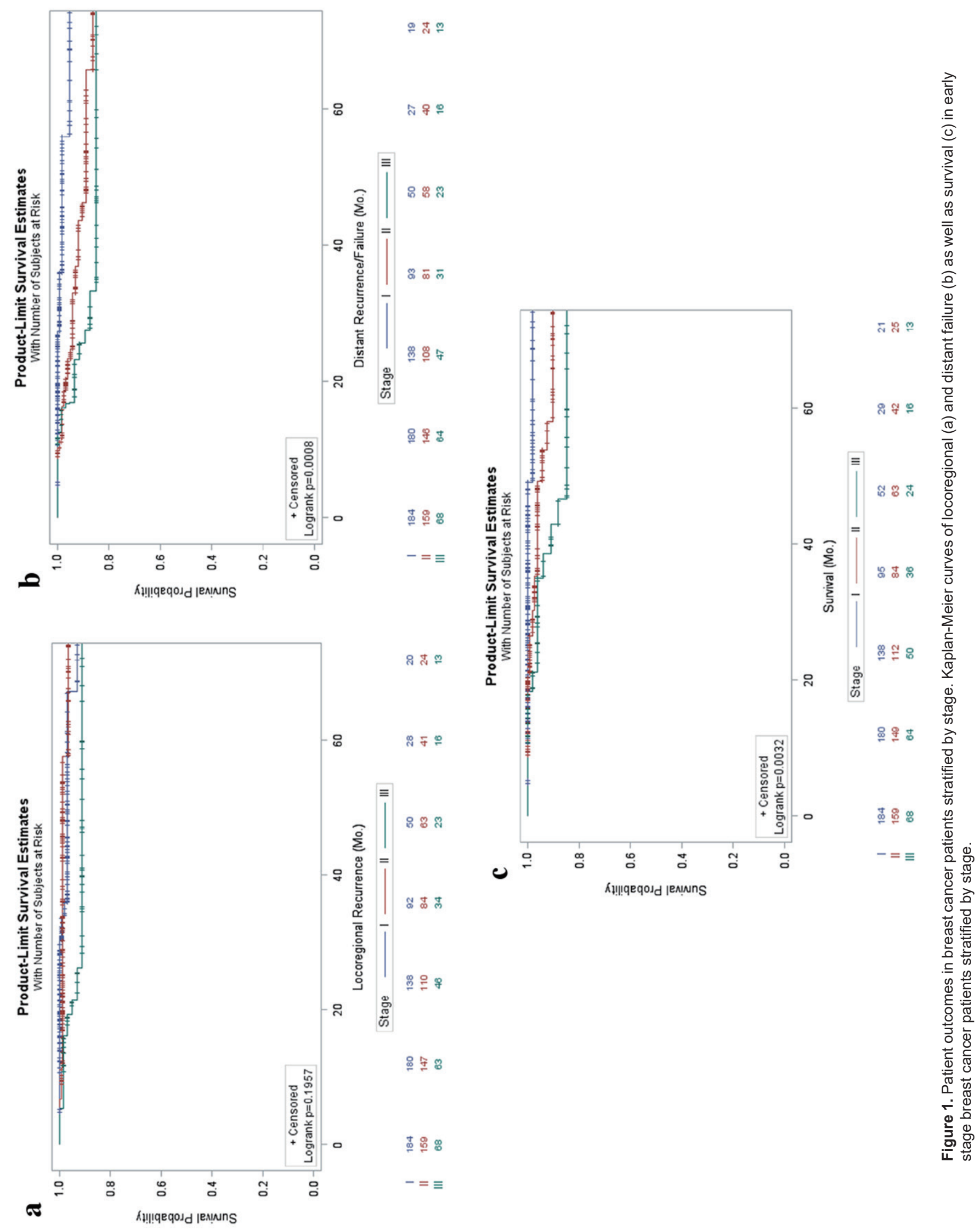


of patients with $>1 \%$ positivity received hormonal therapy, while less than $10 \%$ of patients that were ER negative received hormonal therapy (Supplementary Material 2, www.jocmr.org).

Evaluating the effect of ER positivity on local and distant recurrence as well as overall survival revealed tumors with $0 \%$ ER staining tended to have worse outcomes in local recurrence $(\mathrm{P}=0.001)$ and overall survival $(\mathrm{P}=0.002)$, while patients with $1-79 \%$ positivity and those with $\geq 80 \%$ positivity demonstrated nearly identical trends (Fig. 2a, c). However, there was no difference between subgroups in the rate of distant recurrences $(\mathrm{P}=0.292$, Fig. $2 b)$.

\section{Outcomes relative to $P R$ percent positivity in breast can- cer}

Prior to evaluating the effects on outcomes based on the level of PR positivity, patient and tumor characteristics were compared between these subgroups (Supplementary Material 2, www. jocmr.org). This analysis revealed that grade, $\mathrm{T}$ stage, and use of hormonal therapy, but not age, year of diagnosis, length of follow-up, histological subtype, or overall stage, were significantly different between subgroups. The use of hormone inhibition therapy (selective ER modulators or aromatase inhibitors) was even more ubiquitously used in PR-positive patients with more than $95 \%$ of patients with $>1 \%$ positivity having received hormonal therapy, while approximately $35 \%$ of patients that were ER negative received hormonal therapy.

Evaluating the effect of PR positivity on local and distant recurrence as well as overall survival failed to reveal any statistically significant relationships; however, there was a trend to decreased distant recurrence and improved overall survival with higher levels of PR percent positivity. No association was identified between PR percent positivity in the context of local recurrence $(\mathrm{P}=0.533$, Fig. 3a). A trend towards decreased distant recurrence was seen with increased PR percent positivity $(P=0.064)$, though not statistically significant (Fig. 3b). Similarly, a non-statistically significant trend towards improved overall survival was demonstrated with increased PR positivity $(\mathrm{P}=0.105)$ (Fig. 3c).

\section{Cox PH multivariable analysis of factors contributing to patient outcomes in breast cancer}

Percent positivity of ER and PR (continuous and categorical) as well as stage were analyzed for their relationship to patient outcomes based on local and distant recurrence as well as overall survival via univariate and multivariable analyses using the Cox PH model. On univariate analysis, only percent of ER positivity was associated with local recurrence as either a categorical or continuous variable (Table 2), and after controlling for the effects of each variable, multivariable analysis of local recurrence showed that increasing ER positivity (categorical and continuous) had a decreased hazard ratio for recurrence (Table 2). Increased stage was associated with increased distant recurrence (Table 3). Additionally, stage remained statistically significantly associated with increased distant recurrence on mul- tivariable analysis. Lastly, on univariate analysis, stage 3 vs. 1, and ER percent positivity of $\geq 80 \%$ vs. $0 \%(\mathrm{P}=0.004)$ when evaluated as a categorical variable or as a continuous variable $(\mathrm{P}=0.0026)$ were associated with improved overall survival (Table 4), but on multivariable analysis, increasing stage and ER percent positivity as a categorical variable were associated with improved overall survival, while a PR percent positivity of $1-79 \%$ was associated with decreased overall survival.

\section{Discussion}

Consistent with previous literature, stage was a significant prognostic factor, and increasing stage was associated with an increased likelihood of local and distant recurrence and decreased overall survival (Fig. 1).

When evaluating the influence of the percentage of ER positivity or PR positivity, one first must consider the distribution of the percentages of positivity. Interestingly, the distribution of ER positivity was more highly bimodal with a large majority of tumors demonstrating either no ER positivity or greater than $80 \%$ of cells demonstrating positivity. In contrast, while there were a large proportion of tumors that lacked PR staining, a significant number of tumors also demonstrated intermediate as well as high percentages of cells that were PR positive. It is possible this differential distribution may be caused by technical differences between ER versus PR staining; however, it is also likely that there may be true biological differences between their expression leading to the variable proportion of tumors with various percentages of ER vs. PR positivity. However, the prognostic and clinical significance of recognizing this differential pattern in percentage of cells positive for these markers remains unknown.

The patient demographics stratified by percent ER positivity demonstrate differences in nearly every category including age, year of diagnosis, length of follow-up, histology, grade, T stage, with overall stage having borderline significant differences (Supplementary Material 2, www.jocmr.org). Tumors that lacked ER positivity were more likely to be of higher grade, while those with $>80 \%$ ER positivity were likely to be of low grade and T stage. Particularly the year of diagnosis (and therefore length of follow-up), could be misleading due to technical advancements allowing for more accurate and precise quantification of the percentage of cells expressing ER. Specifically, older diagnoses were more likely to have intermediate levels of staining, opening the possibility that all cells within the tumor could have expressed ER, but only a subset were being recognized. It will be interesting to continue to evaluate how, if at all, the distribution of percentage of cells expressing ER changes in the future as technical advances continue to improve the accuracy and precision of ER positivity quantification in breast cancer. More importantly, though, a lack of ER-positive cells was associated with increased locoregional recurrence (Fig. 2a, Table 2) and shorter survival (Fig. 2c, Table 4) suggesting the possibility that the quantitative percentage of ER positive cells within a tumor may be a favorable prognostic factor. This is consistent with previous reports that have demonstrated the percentage of ER-positive cells as well as the ER H-score (\% staining positive $\mathrm{X}$ intensity) is inversely 


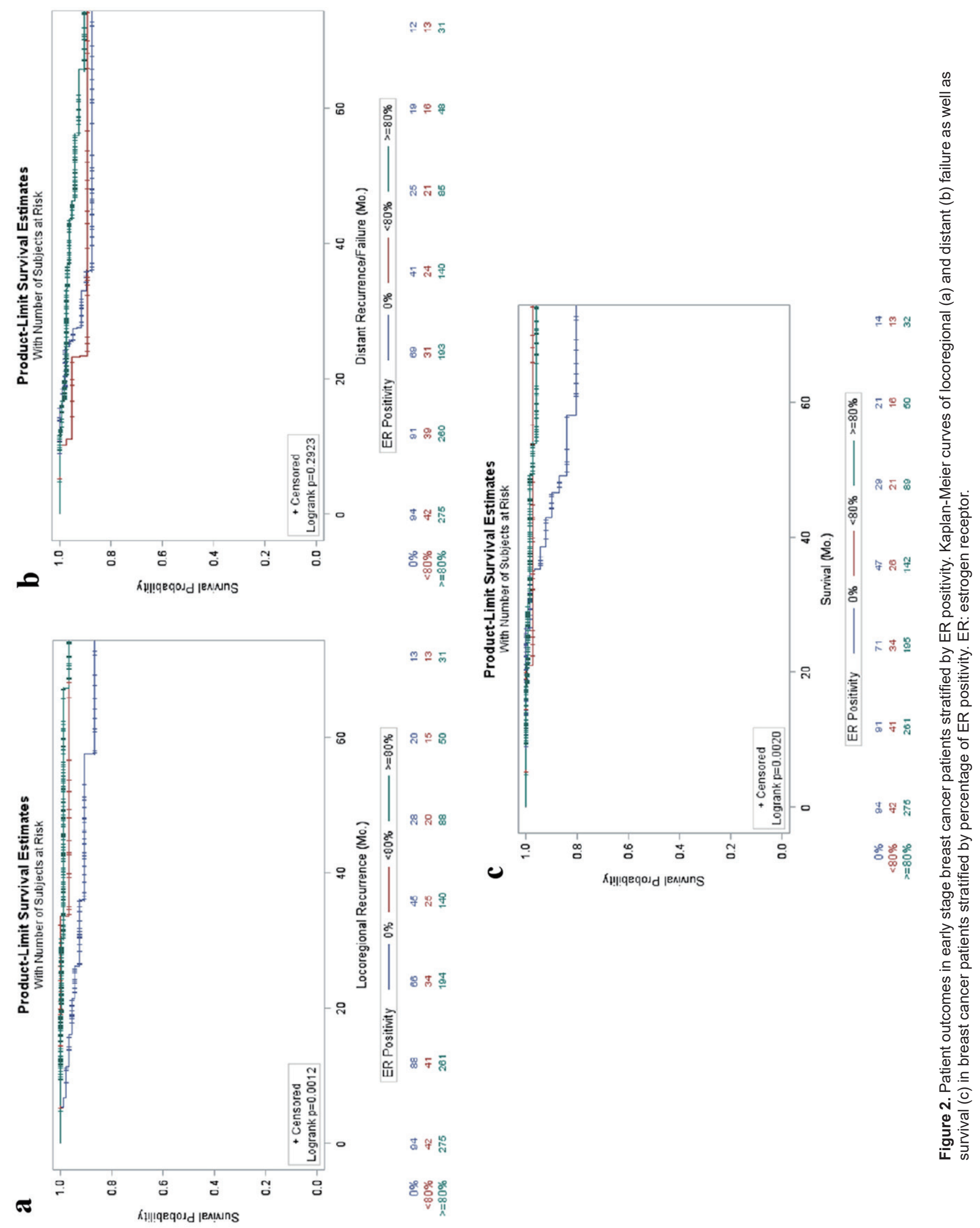




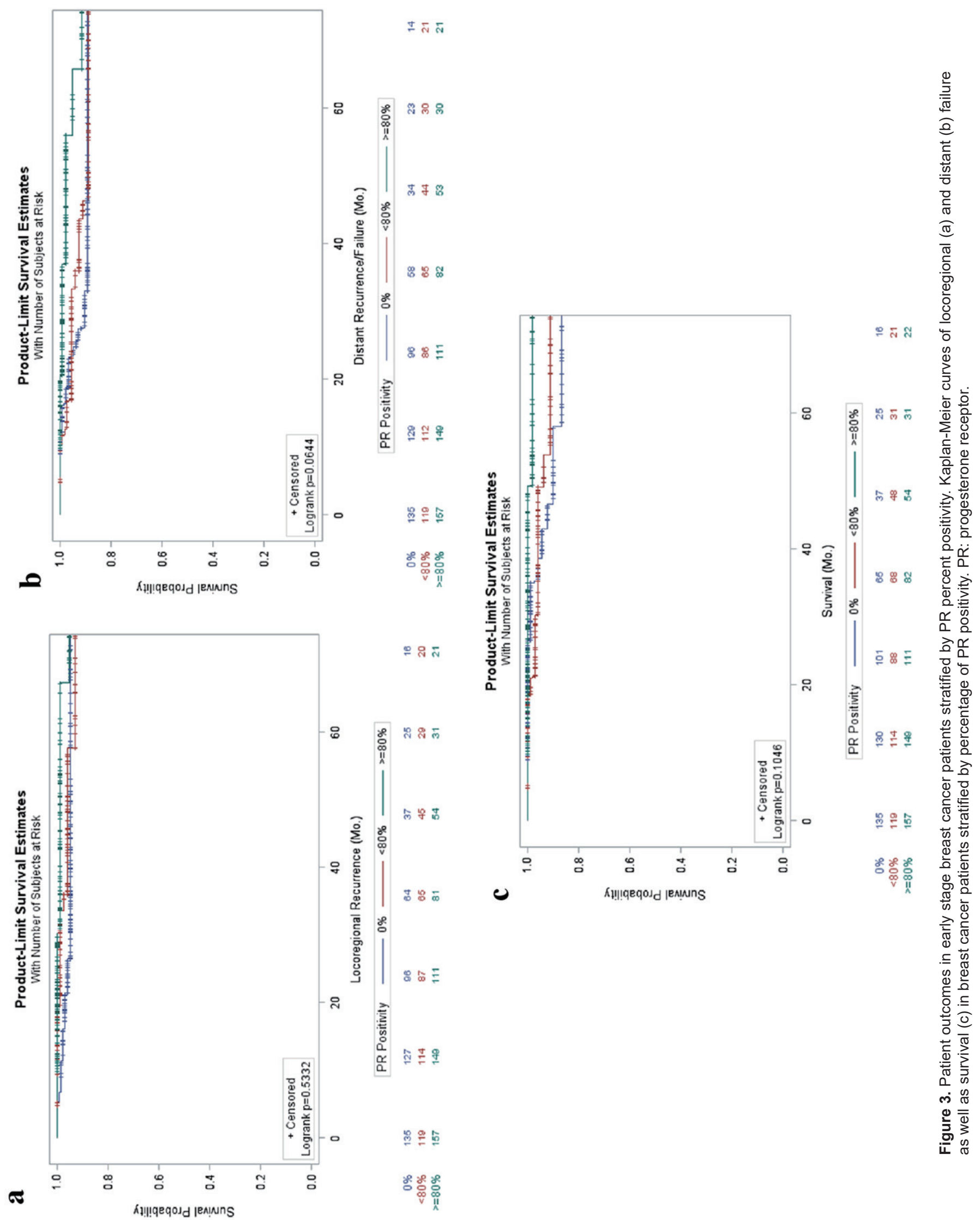


Table 2. Cox PH Univariate and Multivariate Analysis for Percentage of ER Positivity, Percentage of PR Positivity, and Stage for Local Failure

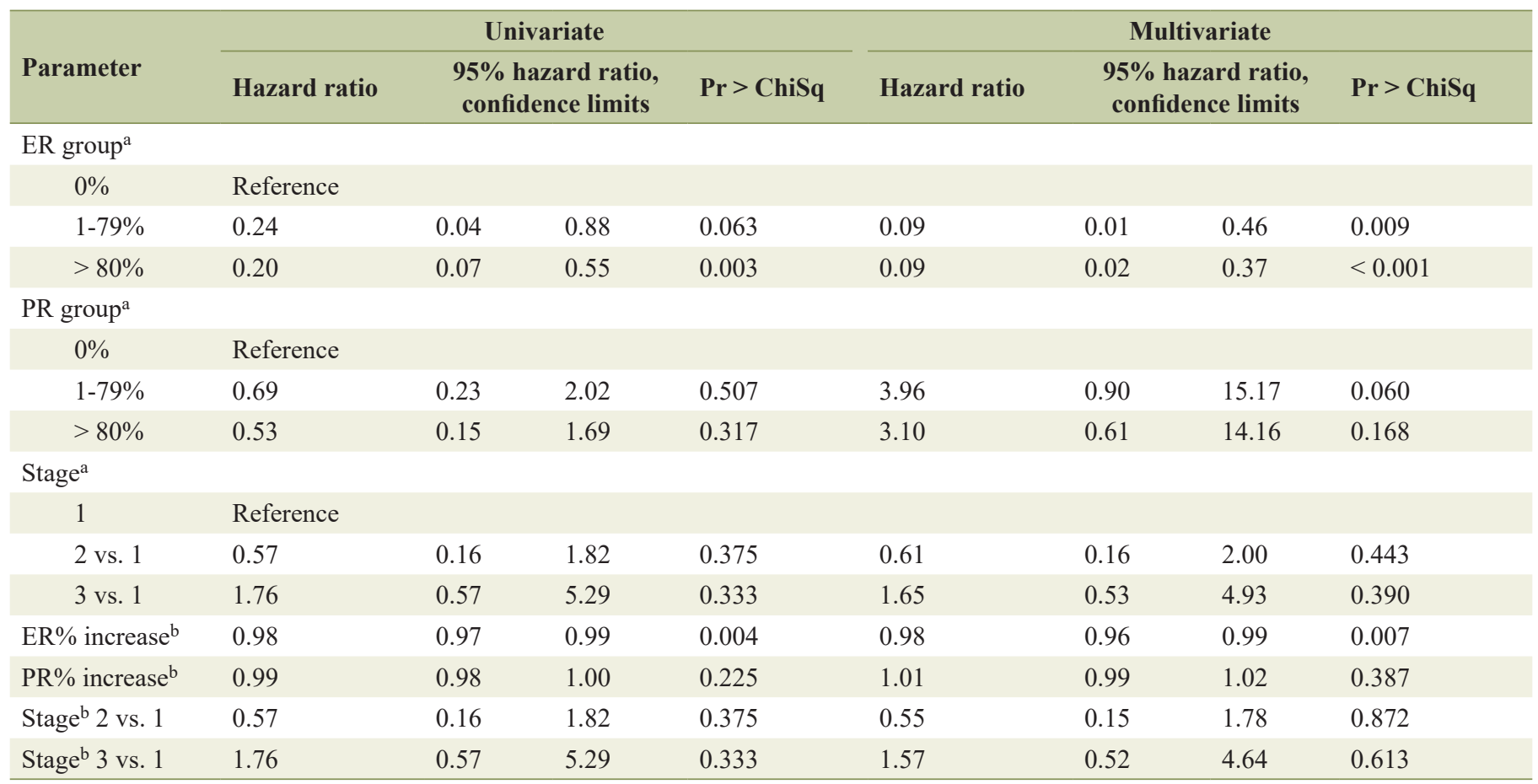

This evaluation was performed considering ER and PR positivity as both ${ }^{a}$ categorical (top) and ${ }^{b}$ continuous variables (bottom). ER: estrogen receptor; PR: progesterone receptor.

Table 3. Cox PH Univariate and Multivariate Analysis for Percentage of ER Positivity, Percentage of PR Positivity, and Stage for Distant Failure

\begin{tabular}{|c|c|c|c|c|c|c|c|c|}
\hline \multirow[b]{2}{*}{ Parameter } & \multicolumn{4}{|c|}{ Univariate } & \multicolumn{4}{|c|}{ Multivariate } \\
\hline & Hazard ratio & \multicolumn{2}{|c|}{$\begin{array}{l}95 \% \text { hazard ratio, } \\
\text { confidence limits }\end{array}$} & $\operatorname{Pr}>$ ChiSq & Hazard ratio & \multicolumn{2}{|c|}{$\begin{array}{l}95 \% \text { hazard ratio, } \\
\text { confidence limits }\end{array}$} & $\operatorname{Pr}>$ ChiSq \\
\hline $0 \%$ & Reference & & & & & & & \\
\hline $1-79 \%$ & 1.14 & 0.38 & 3.23 & 0.813 & 1.01 & 0.27 & 3.34 & 0.988 \\
\hline$>80 \%$ & 0.56 & 0.24 & 1.37 & 0.194 & 0.97 & 0.27 & 3.31 & 0.960 \\
\hline \multicolumn{9}{|l|}{ PR group ${ }^{a}$} \\
\hline $0 \%$ & Reference & & & & & & & \\
\hline $1-79 \%$ & 1.02 & 0.45 & 2.31 & 0.973 & 1.01 & 0.35 & 3.32 & 0.987 \\
\hline$>80 \%$ & 0.33 & 0.10 & 0.92 & 0.051 & 0.36 & 0.08 & 1.48 & 0.161 \\
\hline \multicolumn{9}{|l|}{ Stage $^{a}$} \\
\hline 1 & Reference & & & & & & & \\
\hline 2 vs. 1 & 4.23 & 1.44 & 16.40 & 0.020 & 4.22 & 1.44 & 16.34 & 0.020 \\
\hline 3 vs. 1 & 7.85 & 2.57 & 30.00 & 0.001 & 7.00 & 2.27 & 27.90 & 0.002 \\
\hline $\mathrm{ER} \%$ increase $^{\mathrm{b}}$ & 0.99 & 0.98 & 1.00 & 0.090 & 1.00 & 0.99 & 1.01 & 0.951 \\
\hline $\mathrm{PR} \%$ increase $^{\mathrm{b}}$ & 0.99 & 0.98 & 0.99 & 0.030 & 0.99 & 0.98 & 1.00 & 0.119 \\
\hline Stage $^{b} 2$ vs. 1 & 4.23 & 1.44 & 16.40 & 0.020 & 4.24 & 1.44 & 16.45 & 0.019 \\
\hline Stage $^{\text {b }} 3$ vs. 1 & 7.85 & 2.57 & 30.99 & 0.001 & 7.00 & 2.29 & 27.72 & 0.002 \\
\hline
\end{tabular}

This evaluation was performed considering ER and PR positivity as both ${ }^{\mathrm{a}}$ categorical (top) and ${ }^{\mathrm{b}}$ continuous variables (bottom). ER: estrogen receptor; PR: progesterone receptor. 
Table 4. Cox PH Univariate and Multivariate Analysis for Percentage of ER Positivity, Percentage of PR Positivity, and Stage for Survival

\begin{tabular}{|c|c|c|c|c|c|c|c|c|}
\hline \multirow[b]{2}{*}{ Parameter } & \multicolumn{4}{|c|}{ Univariate } & \multicolumn{4}{|c|}{ Multivariate } \\
\hline & Hazard ratio & \multicolumn{2}{|c|}{$\begin{array}{l}95 \% \text { hazard ratio, } \\
\text { confidence limits }\end{array}$} & $\operatorname{Pr}>$ ChiSq & Hazard ratio & \multicolumn{2}{|c|}{$\begin{array}{l}95 \% \text { hazard ratio, } \\
\text { confidence limits }\end{array}$} & $\operatorname{Pr}>$ ChiSq \\
\hline $0 \%$ & Reference & & & & & & & \\
\hline $1-79 \%$ & 0.30 & 0.06 & 1.07 & 0.107 & 0.08 & 0.01 & 0.48 & 0.008 \\
\hline$>80 \%$ & 0.20 & 0.07 & 0.56 & 0.004 & 0.10 & 0.03 & 0.51 & 0.003 \\
\hline \multicolumn{9}{|l|}{ PR group ${ }^{\mathrm{a}}$} \\
\hline $0 \%$ & Reference & & & & & & & \\
\hline $1-79 \%$ & 0.73 & 0.26 & 2.00 & 0.556 & 4.60 & 0.92 & 18.33 & 0.046 \\
\hline$>80 \%$ & 0.25 & 0.05 & 0.90 & 0.064 & 1.13 & 0.17 & 5.45 & 0.890 \\
\hline \multicolumn{9}{|l|}{ Stage $^{\mathrm{a}}$} \\
\hline 1 & Reference & & & & & & & \\
\hline 2 vs. 1 & 5.28 & 1.18 & 49.76 & 0.072 & 5.60 & 1.23 & 53.12 & 0.065 \\
\hline 3 vs. 1 & 11.59 & 2.58 & 109.54 & 0.009 & 11.77 & 2.59 & 111.77 & 0.008 \\
\hline $\mathrm{ER} \%$ increase $^{\mathrm{b}}$ & 0.98 & 0.97 & 0.99 & 0.003 & 0.99 & 0.97 & 1.00 & 0.119 \\
\hline $\mathrm{PR} \%$ increase $^{\mathrm{b}}$ & 0.98 & 0.97 & 0.99 & 0.014 & 0.99 & 0.97 & 1.01 & 0.336 \\
\hline Stage $^{\mathrm{b}} 2$ vs. 1 & 5.28 & 1.18 & 49.76 & 0.073 & 4.97 & 1.11 & 46.88 & 0.085 \\
\hline Stage $^{\text {b }} 3$ vs. 1 & 11.59 & 2.58 & 109.54 & 0.008 & 10.22 & 2.29 & 96.30 & 0.012 \\
\hline
\end{tabular}

This evaluation was performed considering ER and PR positivity as both a categorical (top) and ${ }^{b}$ continuous variables (bottom). ER: estrogen receptor; PR: progesterone receptor.

correlated with cancer-specific mortality [20].

Other groups have demonstrated that individuals with $<$ $6 \%$ ER staining often act similar to triple negative tumors [10, 21]; however, ours is one of the first studies to demonstrate a trend towards a difference between a moderate-high levels of staining (1-79\%) compared to nearly ubiquitous staining $(>$ $80 \%$ ). Of note, these tumors would all be classified as luminal subtype which carries a favorable prognosis. This may be misleading; however, there appears to be a difference in prognosis with decreasing ER positivity. Using a continuous model to evaluate the effects of increasing ER positivity reveals a statistically significant decrease in local recurrence and overall survival with a trend towards a decrease in distant recurrence. This suggests that the degree of ER staining can be prognostic despite the typical clinical Boolean description of either positive or negative. Instead, our results suggest that even using the simple percentage of cell staining positive for ER may have prognostic distinguishing power and should not be overlooked.

Evaluating the patient demographics stratified by percent cells with PR positivity failed to reveal differences in age, year of diagnosis, follow-up, histology, or overall stage; however, grade and $\mathrm{T}$ stage were significantly different between groups. The relationship demonstrated that a lack of PR staining was associated with higher grade tumors, while $>80 \%$ PR positivity was associated with smaller tumors and lower $\mathrm{T}$ staging. While not statistically significant, a trend towards increased distant recurrence and shorter survival was also seen with progressively smaller percentages of cells staining positive for
PR (Fig. 3), suggesting that ubiquitous PR positivity may also be a positive prognostic factor. This may be a confounded effect secondary to increased ER receptor expression and intact downstream pathways as PR is increased with ER pathway activation or may represent an independent factor. Several groups have evaluated both the effect of PR positivity as well as downstream ER effects secondarily to ER positivity in an attempt to more robustly predict outcomes for hormone receptor positivity patients, and found that an intact ER pathway was associated with improved outcomes [22-24].

Limitations of this study include its retrospective nature and the relatively small number of patients in each of the stratified groups. Additionally, the long period of time over which data were collected (2010 - 2017) and the constant evolution and technological advances of quantifying biological markers could have allowed for significant improvements in the accuracy and precision of assessing the percentage of cells demonstrating ER or PR positivity leading to differential assessments of positivity over time. Continued evaluation and consideration of the possibility that not only the overall "positive" or "negative" status of a tumor, but also the percentage of cells expressing ER or PR may be valuable prognostic and therapeutic factors that should be considered.

\section{Supplementary Material}

Suppl 1. Distribution of percent of cells that were ER and/or 
PR positive.

Suppl 2. Demographics and tumor characteristics of breast cancer patients stratified by percentage ER and PR positivity.

\section{Acknowledgments}

None to declare.

\section{Financial Disclosure}

No funding sources to disclose.

\section{Conflict of Interest}

The authors certify that they have no affiliations with or involvement in any organization or entity with any financial interest (such as honoraria; educational grants; participation in speakers' bureaus; membership, employment, consultancies, stock ownership, or other equity interest; and expert testimony or patent-licensing arrangements), or non-financial interest (such as personal or professional relationships, affiliations, knowledge or beliefs) in the subject matter or materials discussed in this manuscript.

\section{Informed Consent}

Informed consent was obtained in accordance with UNMC's institutional policies and per respective IRB-approved protocols.

\section{Author Contributions}

Drs. Baine, Sleightholm, and Neilsen oversaw the project in every capacity from conception to finish. RS, BN, SE, LF, SD, $\mathrm{RZ}, \mathrm{SC}, \mathrm{BG}, \mathrm{JC}, \mathrm{MB}$ were involved in the collection of the data. Drs. Sleightholm, Neilsen, Smith, and Baine were involved in the statistical analysis. All authors were involved in the drafting and final approval of the text, tables, figures and manuscript as a whole.

\section{Data Availability}

Any inquiries regarding supporting data availability of this study should be directed to the corresponding author.

\section{References}

1. Ferlay J, Soerjomataram I, Dikshit R, Eser S, Mathers C, Rebelo M, Parkin DM, et al. Cancer incidence and mortality worldwide: sources, methods and major patterns in GLOBOCAN 2012. Int J Cancer. 2015;136(5):E359-386.
2. Ferlay J, Colombet M, Soerjomataram I, Mathers C, Parkin DM, Pineros M, Znaor A, et al. Estimating the global cancer incidence and mortality in 2018: GLOBOCAN sources and methods. Int J Cancer. 2019;144(8):19411953.

3. Anderson WF, Chatterjee N, Ershler WB, Brawley OW. Estrogen receptor breast cancer phenotypes in the Surveillance, Epidemiology, and End Results database. Breast Cancer Res Treat. 2002;76(1):27-36.

4. Mohsin SK, Weiss H, Havighurst T, Clark GM, Berardo M, Roanh le D, To TV, et al. Progesterone receptor by immunohistochemistry and clinical outcome in breast cancer: a validation study. Mod Pathol. 2004;17(12):15451554.

5. Wu VS, Kanaya N, Lo C, Mortimer J, Chen S. From bench to bedside: What do we know about hormone receptor-positive and human epidermal growth factor receptor 2-positive breast cancer? J Steroid Biochem Mol Biol. 2015;153:45-53.

6. Rhodes A, Jasani B, Balaton AJ, Barnes DM, Anderson E, Bobrow LG, Miller KD. Study of interlaboratory reliability and reproducibility of estrogen and progesterone receptor assays in Europe. Documentation of poor reliability and identification of insufficient microwave antigen retrieval time as a major contributory element of unreliable assays. Am J Clin Pathol. 2001;115(1):44-58.

7. Fragomeni SM, Sciallis A, Jeruss JS. Molecular subtypes and local-regional control of breast cancer. Surg Oncol Clin N Am. 2018;27(1):95-120.

8. Hammond ME, Hayes DF, Dowsett M, Allred DC, Hagerty KL, Badve S, Fitzgibbons PL, et al. American Society of Clinical Oncology/College of American Pathologists guideline recommendations for immunohistochemical testing of estrogen and progesterone receptors in breast cancer (unabridged version). Arch Pathol Lab Med. 2010;134(7):e48-72.

9. Harvey JM, Clark GM, Osborne CK, Allred DC. Estrogen receptor status by immunohistochemistry is superior to the ligand-binding assay for predicting response to adjuvant endocrine therapy in breast cancer. J Clin Oncol. 1999;17(5):1474-1481.

10. Prabhu JS, Korlimarla A, Desai K, Alexander A, Raghavan R, Anupama C, Dendukuri N, et al. A majority of low (1-10\%) ER positive breast cancers behave like hormone receptor negative tumors. J Cancer. 2014;5(2):156165.

11. Fujii T, Kogawa T, Dong W, Sahin AA, Moulder S, Litton JK, Tripathy D, et al. Revisiting the definition of estrogen receptor positivity in HER2-negative primary breast cancer. Ann Oncol. 2017;28(10):2420-2428.

12. Caruana D, Wei W, Martinez-Morilla S, Rimm DL, Reisenbichler ES. Association between low estrogen receptor positive breast cancer and staining performance. NPJ Breast Cancer. 2020;6:5.

13. Yi M, Huo L, Koenig KB, Mittendorf EA, Meric-Bernstam F, Kuerer HM, Bedrosian I, et al. Which threshold for ER positivity? a retrospective study based on 9639 patients. Ann Oncol. 2014;25(5):1004-1011.

14. Deyarmin B, Kane JL, Valente AL, van Laar R, Gallagh- 
er C, Shriver CD, Ellsworth RE. Effect of ASCO/CAP guidelines for determining ER status on molecular subtype. Ann Surg Oncol. 2013;20(1):87-93.

15. Bouchard-Fortier A, Provencher L, Blanchette C, Diorio C. Prognostic and predictive value of low estrogen receptor expression in breast cancer. Curr Oncol. 2017;24(2):e106-e114.

16. Gloyeske NC, Dabbs DJ, Bhargava R. Low ER+ breast cancer: Is this a distinct group? Am J Clin Pathol. 2014;141(5):697-701.

17. Hill DA, Barry M, Wiggins C, Nibbe A, Royce M, Prossnitz E, Lomo L. Estrogen receptor quantitative measures and breast cancer survival. Breast Cancer Res Treat. 2017;166(3):855-864.

18. Ono M, Tsuda H, Yoshida M, Shimizu C, Kinoshita T, Tamura K. Prognostic significance of progesterone receptor expression in estrogen-receptor positive, HER2-negative, node-negative invasive breast cancer with a low Ki-67 labeling index. Clin Breast Cancer. 2017;17(1):41-47.

19. Basile D, Cinausero M, Iacono D, Pelizzari G, Bonotto M, Vitale MG, Gerratana L, et al. Androgen receptor in estrogen receptor positive breast cancer: Beyond expression. Cancer Treat Rev. 2017;61:15-22.

20. Ma H, Lu Y, Marchbanks PA, Folger SG, Strom BL, Mc-
Donald JA, Simon MS, et al. Quantitative measures of estrogen receptor expression in relation to breast cancerspecific mortality risk among white women and black women. Breast Cancer Res. 2013;15(5):R90.

21. Raghav KP, Hernandez-Aya LF, Lei X, ChavezMacgregor M, Meric-Bernstam F, Buchholz TA, Sahin $A$, et al. Impact of low estrogen/progesterone receptor expression on survival outcomes in breast cancers previously classified as triple negative breast cancers. Cancer. 2012;118(6):1498-1506.

22. Prat A, Cheang MC, Martin M, Parker JS, Carrasco E, Caballero R, Tyldesley S, et al. Prognostic significance of progesterone receptor-positive tumor cells within immunohistochemically defined luminal A breast cancer. J Clin Oncol. 2013;31(2):203-209.

23. Clark GM, McGuire WL, Hubay CA, Pearson OH, Marshall JS. Progesterone receptors as a prognostic factor in Stage II breast cancer. N Engl J Med. 1983;309(22):13431347.

24. Iwamoto T, Booser D, Valero V, Murray JL, Koenig K, Esteva FJ, Ueno NT, et al. Estrogen receptor (ER) mRNA and ER-related gene expression in breast cancers that are $1 \%$ to $10 \%$ ER-positive by immunohistochemistry. J Clin Oncol. 2012;30(7):729-734. 